\title{
CLASSIFICAÇÃO EM CORES: UMA METODOLOGIA INOVADORA NA ORGANIZAÇÃO DAS BIBLIOTECAS ESCOLARES DO MUNICÍPIO DE RONDONÓPOLIS-MT
}

Mariza Inês da Silva Pinheiro

\section{Resumo:}

Aborda uma metodologia diferenciada e muito pouco aplicada no Brasil que é a classificação em cores nas bibliotecas escolares, elaborada pela autora deste artigo. Esta iniciativa se realizou através de convênio entre o curso de Biblioteconomia da Universidade Federal de Mato Grosso - Campus Rondonópolis e a Prefeitura local; vinte acadêmicos do curso estagiam a cada ano com a coordenadora, professora Mariza Inês da Silva Pinheiro, com o objetivo de proporcionar aos alunos de cada escola do município o acesso às obras com maior rapidez e precisão, em prol do gosto pela leitura. Mostra-se a importância da classificação em cores e o papel do bibliotecário escolar. Verificou-se, enfim, que este trabalho tornou-se gratificante para todos os envolvidos no processo.

\section{Palavras-Chave:}

Classificação em cores; Biblioteca escolar; Bibliotecário escolar; Rondonópolis-MT

\section{COLORS CLASSIFICATION: AN INNOVATIVE METHODOLOGY TO HELP OUT THE ORGANIZATION OF SCHOOL LIBRARIES IN THE CITY OF RONDONÓPOLIS, MATO GROSSO STATE, BRAZIL}

\begin{abstract}
:
This research refers to a differentiate methodology which is little used in Brazil, that is, the colors classification in school libraries developed by the author of this article. The initiative was carried out through an agreement between the Librarianship Course of Universidade Federal de Mato Grosso Campus Rondonópolis, and the local Major House. Twenty students of the Librarianship Course participated in a practice stage with the coordinator Professor Mariza Inês da Silva Pinheiro, aiming to fastly and precisely offer to the students of each school in the city access to various works, in order to reach the interest for reading. It presents the importance of colors classification and the role of the school librarian. Thus, it could be said that this research became a rewarding work for everyone involved in the process.
\end{abstract}

Keywords:

Colors classification; School library; School Librarian; Rondonopolis-MT-Brazil

(c) Revista Digital de Biblioteconomia e Ciência da Informação,Campinas, v.7, n. 1, p. 163-179, jul./dez. 2009- ISSN: 1678-765X. 


\section{INTRODUÇÃO}

Dentro das atividades biblioteconômicas, em uma biblioteca, a organização do acervo é uma operação que deve receber atenção especial, pois a forma de organizar possibilita ao usuário um acesso mais fácil às informações; portanto, evidencia-se a necessidade de que se adotem políticas de organização. Neste contexto, classificar as fontes bibliográficas é uma forma de ordenar as mesmas por áreas para melhor recuperar as informações.

Em vista disso, o curso de Biblioteconomia da Universidade Federal de Mato Grosso Campus de Rondonópolis-MT através dos professores Alexandre Oliveira de Meira Gusmão e Mariza Inês da Silva Pinheiro, apresentou um projeto à Secretaria Municipal de Educação, visando a oferecer estágios remunerados para estudantes desse Curso, com o objetivo de promover a organização e administração dos acervos das bibliotecas escolares do município, dando ênfase maior ao incentivo à leitura nos alunos das séries iniciais.

A partir desta iniciativa foi estabelecido o convênio n.54/2004 entre o Curso de Biblioteconomia/UFMT e Prefeitura Municipal de Rondonópolis, com vigência prevista para o período de 01/07/2004 a 31/12/2009. No bojo desse projeto, foi implementado uma organização nas bibliotecas escolares com uma nova metodologia de classificação em cores, criada pela professora Mariza Inês da Silva Pinheiro, coordenadora do estágio nessas bibliotecas, e tal classificação foi padronizada para todas as escolas participantes do convênio. Estabeleceu-se um padrão de cores para cada área do conhecimento, nos livros didáticos e paradidáticos, e também uma classificação por cores conforme o gênero de cada obra de literatura.

As cores escolhidas foram as mais vibrantes possíveis, com intuito de além de facilitar para as crianças a busca nas estantes, atraí-las ao mundo fantástico que a leitura proporciona. Neste aspecto, salienta-se que a metodologia utilizada além de ser inovadora no meio escolar, buscou um meio de propiciar independência às crianças na procura dos livros e facilitar aos professores a recuperação da informação.

O objetivo principal deste artigo é divulgar a classificação em cores e mostrar alguns procedimentos adotados na organização das bibliotecas escolares municipais em foco, os

(c) Revista Digital de Biblioteconomia e Ciência da Informação,Campinas, v.7, n. 1, p. 163-179, jul./dez. 2009- ISSN: 1678-765X. 
quais têm acarretado uma presença constante dos alunos nestes espaços e uma recuperação fácil e ágil no encontro das obras. Quanto às atividades de incentivo à leituras realizadas, serão expostas em outra oportunidade.

\section{AS ESCOLAS MUNICIPAIS DE RONDONÓPOLIS-MT E SUAS BIBLIOTECAS}

A Prefeitura Municipal de Rondonópolis conta em sua rede com trinta e cinco escolas, estando vinte e quatro destas na zona urbana e onze na zona rural. A maioria oferece o ensino voltado para crianças da pré-escola até o quarto ano. Não foi possível verificar se em todas estas unidades escolares existem bibliotecas.

Neste ponto, convém lembrar que, em 2002, foi feita uma pesquisa em algumas bibliotecas das escolas de Rondonópolis, analisando o acervo, espaço físico e pessoal. Com esse estudo constatou-se que essas instituições informacionais e educacionais encontravam-se muito distantes dos padrões regulares, o que constitui um problema que a maioria das bibliotecas escolares brasileiras enfrenta.

Quanto ao espaço físico, todos eram reduzidos e inadequados, bem como todo o mobiliário, mostrava-se totalmente impróprio para atividades com crianças. Na ocasião não existia nenhum bibliotecário atuando nas bibliotecas pesquisadas, e muitas se encontravam fechadas por não haver funcionário para atender as crianças.

Com o convênio de 2004, foram contratados, por um ano, treze estagiários, e de 2005 a 2008, contrataram-se vinte estagiários por ano para atuar na organização das bibliotecas escolares e no incentivo à leitura.

\section{CLASSIFICAÇÃO EM CORES EM BIBLIOTECAS ESCOLARES}

Tendo em vista a importância da classificação das fontes bibliográficas, as bibliotecas utilizam os códigos de classificação CDD (Classificação Decimal de Dewey) ou CDU (Classificação Decimal Universal), que classificam as obras por áreas e subáreas do conhecimento.

(c) Revista Digital de Biblioteconomia e Ciência da Informação,Campinas, v.7, n. 1, p. 163-179, jul./dez. 2009- ISSN: 1678-765X. 
Algumas bibliotecas universitárias e especializadas utilizam além destes códigos, a classificação em cores nas áreas principais, ou seja, nove áreas estabelecidas pelos códigos CDD e CDU.

Quanto às bibliotecas escolares e infantis, a classificação em cores tem sido considerada a melhor metodologia, sendo um fator importantíssimo na recuperação da informação por construir um elo entre a linguagem visual e a busca do material nas estantes.

No entender de Pinheiro e Sachetti (2004, p.4), “[...] a busca de um sistema de sinalização que utilize recurso de linguagem visual visa não só a estética, mas principalmente a facilidade de uso do seu ambiente, o que proporciona uma melhor interação entre o usuário e a informação". As autoras prosseguem observando que "toda biblioteca necessita de organização, mesmo aquelas pequenas e de usuários mirins, pois para eles é necessário que a equipe da biblioteca use um sistema de sinalização que contemple códigos de fácil entendimento para as crianças.”

Além disso, as fontes bibliográficas pertencentes a uma biblioteca escolar devem ser organizadas conforme os interesses do perfil dos usuários, especialmente dos pequenos leitores. Simão; Schercher e Neves (1993, p. 29) consideram que "seus documentos devem ser minuciosamente selecionados e classificados de acordo com o interesse de seu público e que seja capaz de atraí-los, de satisfazê-los”.

Assim, vê-se que o ambiente da biblioteca, de uma unidade escolar, precisa estar de acordo com a faixa etária do aluno que o freqüenta, de forma que as crianças possam sentir-se atraídas pelo local e sintam prazer em visitá-lo. Por isso, a biblioteca necessita de uma classificação acessível à criança, além de ter um espaço agradável, divertido, bem colorido, que chame a atenção dos freqüentadores.

Neste contexto, Pinheiro e Sachetti (2004, p.5), salientam que, por ser um dos principais elementos do código visual, “a cor deve ser sempre bem destacada para que possa chamar a atenção do usuário e deve ser tratada em conjunto com todo o espaço físico, mobiliário e equipamentos da biblioteca no sentido de buscar um melhor aspecto visual de todo o ambiente.” 
Tendo por foco uma classificação compreensível para o público infantil, Pinheiro e Sachetti (2004, p.6) afirmam, ainda, que “a classificação por cores facilita o encontro da obra desejada, pois as cores são uma das primeiras linguagens que a criança aprende quando pequena.” Ao atentarmos para essa realidade, o relacionamento da criança com livros torna-se-á mais fácil, aumentado a possibilidade de que ela visite a biblioteca por prazer e saia dali satisfeita.

Simão; Schercher e Neves (1993, p.29), também enfatizam a importância do código de cores, definindo-o como:

\begin{abstract}
Um sistema de cores que reúne as obras através das cores convencionadas para representar o assunto e seus aspectos. Quando se utiliza a codificação em cores para armazenagem das obras em seu local específico, deve-se levar em consideração a necessidade de ser estabelecida uma legenda que identifique a cor escolhida e o assunto.
\end{abstract}

Julga-se conveniente ressaltar que a classificação por cores facilita o contato dos pequenos com um espaço lúdico, transportando-os para um mundo colorido. Com o auxilio das cores, eles poderão criar uma relação particular com as histórias, estabelecendo-se um contato mais agradável e prazeroso com o livro.

É necessário abrir caminhos, criar condições e implantar ações que possam estimular e motivar a criança a freqüentar uma biblioteca por prazer e, conseqüentemente, adquirir nas suas leituras um melhor aprendizado. Sob essa visão, Pacheco (2007, p.305) relata uma experiência vivenciada na Biblioteca Monteiro Lobato, no Retiro da Lagoa em Florianópolis-SC. Num primeiro momento, "Reuniram-se as obras por meio de cores convencionadas no intuito de tornar a biblioteca um local convidativo, atrativo, dinâmico, agradável, alegre, colorido, onde as crianças matriculadas na unidade escolar sentissem prazer em freqüentá-la.”

De acordo com a autora, “quando a criançada chegava à biblioteca, a bibliotecária explicava que a organização facilitava a localização do livro, e que o sistema de classificação adotado era de cores” (PACHEC0, 2007 p.306). Segundo o relato, houve uma preocupação com o entendimento das crianças e, portanto, ocorreu uma nova explicação, da seguinte forma: 
Foi esclarecido que a biblioteca era como uma avenida com casas, que cada prateleira, assim como a rua, tinha um código que poderia ser formado por números e letras ou por marca de cores. [...] o sistema de cores reunia as obras por meio das cores pré-definidas que representavam os assuntos. [...] Portanto cada livro tinha um endereço que era marcado em sua lombada com etiquetas coloridas para que após o uso fosse guardado no lugar certo pelos responsáveis da biblioteca.

Apesar de se verificarem algumas experiências desse tipo, observa-se que, no Brasil, há uma grande carência de literatura que aponte alternativas para a classificação em bibliotecas escolares e infantis. Atualmente o código mais usado é a supracitada Classificação Decimal de Dewey - CDD, mas sabe-se que este sistema de classificação dificulta o entendimento das crianças na busca das obras. Todavia, conforme algumas teorias da área, já existem exemplos de profissionais que se mostram preocupados em atender esse público tão especial que é o infantil.

Em alguns países, vê-se a preocupação em adaptar a CDD e a CDU para as crianças, designando uma cor para cada classe. Segundo Venegas (2005, p.2), “En la literatura europea, especialmente española, es ampliamente conocida la Margarita Cromática para bibliotecas infantiles, que és una adaptación del CDU.”

Visto que a biblioteca escolar precisa proporcionar um espaço aconchegante e que ofereça uma oportunidade de acesso fácil ao acervo, não se pode lançar mão da classificação em cores como facilitadora dessa condição, reproduzindo um ambiente informacional capaz de atingir o seu objetivo que é o incentivo à leitura.

\subsection{A metodologia aplicada nas escolas da Prefeitura Municipal de Rondonópolis}

A metodologia adotada vem promovendo nas crianças outra realidade quanto à oportunidades de aproximação das obras no seu cotidiano. As cores transmitem alegria ao ambiente da biblioteca, e inclusive por isso acredita-se que a escolha da classificação em cores foi a melhor maneira de aproximar os pequenos da leitura. Sabe-se que não é apenas com a organização que eles irão motivar-se para a leitura, mas ela constitui um item fundamental para que se sintam estimulados a ler e aprender.

(c) Revista Digital de Biblioteconomia e Ciência da Informação,Campinas, v.7, n. 1, p. 163-179, jul./dez. 2009- ISSN: 1678-765X. 
É oportuno enfatizar-se que esta metodologia é inédita no estado de Mato Grosso e, podese até dizer, no Brasil. Sabe-se que existem algumas iniciativas nesta linha no país, mas não se encontra qualquer disseminação nas publicações da área.

Inicialmente, as atividades desenvolvidas pelos estagiários de Biblioteconomia deram ênfase à organização, pois a maioria das bibliotecas estava desorganizada. Além disso, por se tratar de bibliotecas cujo público alvo são crianças, buscaram-se alternativas que pudessem atender de maneira satisfatória o público infantil. Essas atividades foram coordenadas pela professora Mariza Inês da Silva Pinheiro, nas bibliotecas, e também houve reuniões na Secretaria de Educação e na própria universidade.

Após estabelecer as atividades de organização, os estagiários elaboraram projetos com os professores das escolas, com o objetivo de incentivar a leitura.

Estes alunos, assim, tiveram o desafio e o compromisso de trabalhar colocando em prática a teoria aprendida no curso.

Na classificação das obras, estabeleceu-se que para cada gênero literário se empregasse uma cor, assim como, para cada área didática, conforme demonstram as figuras 1 e 2, onde se apresentam as legendas com as cores escolhidas. 


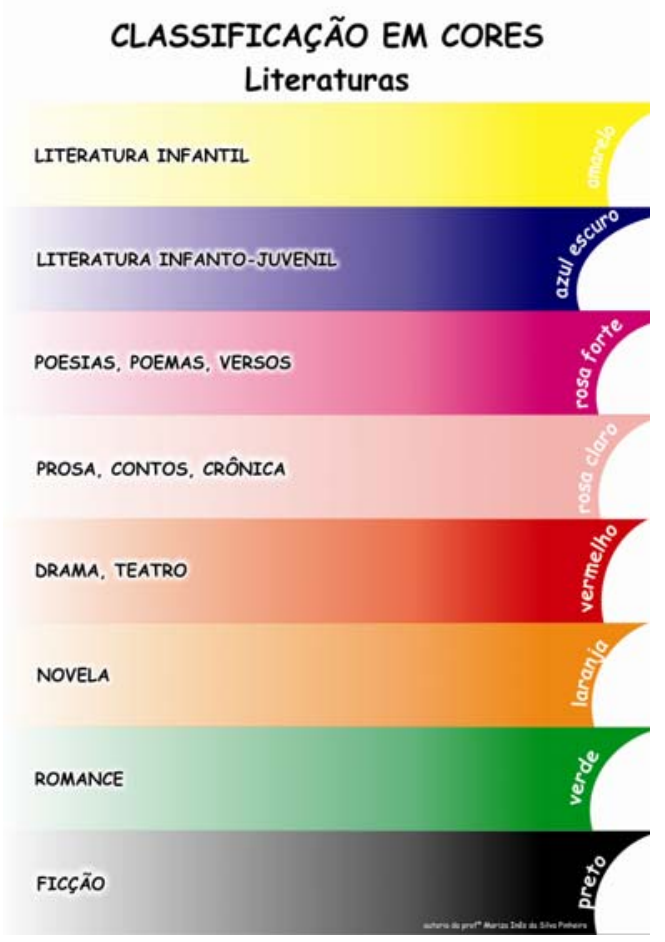

Figura 1 - Classificação em cores - Literatura

\section{CLASSIFICAÇÃO EM CORES}

Livros didáticos/paradidáticos

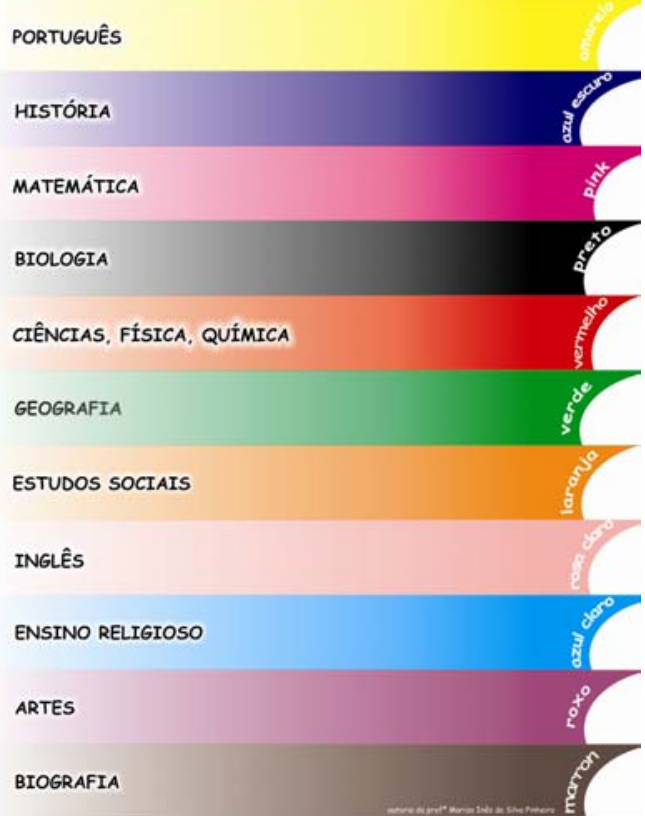

Figura 2 - Classificação em cores - Livros didáticos/naradidáticos

As obras de literaturas estrangeiras foram estabelecidas conforme os respectivos gêneros acima mencionados, e as siglas das terminações geográficas que cobrem todos os países e territórios do planeta, de acordo com o exemplo dos dez países em ordem alfabética que se vêem nas figuras 3 e 4.

\begin{tabular}{|l|c||}
\hline \multicolumn{1}{|c|}{ Domínio geográfico = País } & Classificação \\
\hline \hline África do Sul & ZA \\
\hline \hline Alemanha & DE \\
\hline \hline Argentina & AR \\
\hline \hline Austrália & AU \\
\hline \hline Bolívia & BO \\
\hline \hline Brasil & BR \\
\hline \hline Canadá & CA \\
\hline \hline Chile & CL \\
\hline \hline China & CN \\
\hline \hline Colômbia & CO \\
\hline \hline
\end{tabular}

Figura 3 - Siglas das terminações geográficas que cobrem todos os países e territórios Fonte: A autora, 2008. 
As obras, além de classificadas pelas siglas das terminações geográficas, receberam a classificação em cores por gênero, como exemplificado na figura 4, que mostra algumas obras romanceadas com a cor verde.

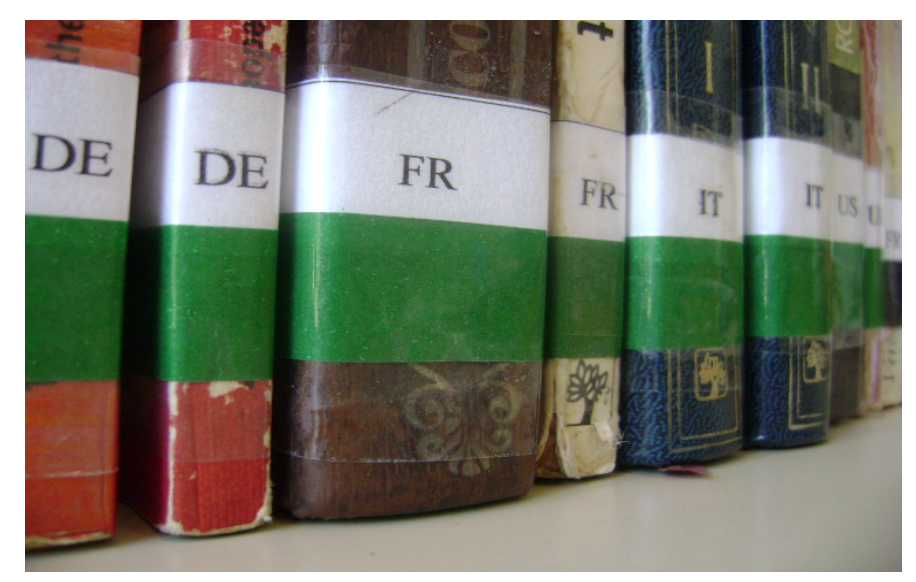

Figura 4 - Classificação pelas terminações geográficas e por cores Fonte: A autora, 2008.

Além das atividades da classificação em si, existem algumas normas para a colagem da tarja na lombada das obras, e assim foi colocada em cada livro uma tarja de 1,5 centímetro de largura: nos livros de espessura fina (até 300 páginas), uma tarja com 5 centímetros de comprimento; nos livros médios (300 a 700 páginas) a tarja tinha 7 centímetros de comprimento, e nos grossos (acima de 700 páginas) seu comprimento era de 9 centímetros, conforme figuras 5 e 6.

\begin{tabular}{||c||c|c||}
\hline Espessura do livro & Comprimento da tarja & Largura da tarja \\
\hline \hline $\begin{array}{c}\text { Livros finos } \\
\text { (até 300 páginas) }\end{array}$ & $5 \mathrm{~cm}$ & $1.5 \mathrm{~cm}$ \\
\hline \hline $\begin{array}{c}\text { Livros médios } \\
\text { (300 a 700 páginas) }\end{array}$ & $7 \mathrm{~cm}$ & $1.5 \mathrm{~cm}$ \\
\hline \hline $\begin{array}{c}\text { Livros grossos } \\
\text { (acima de 700 páginas) }\end{array}$ & $9 \mathrm{~cm}$ & $1.5 \mathrm{~cm}$ \\
\hline
\end{tabular}

Figura 5 - Dimensões da tarja

Fonte: a autora. 


\section{Local da tarja no livro}

$1.5 \mathrm{~cm}$ acima do pé da lombada

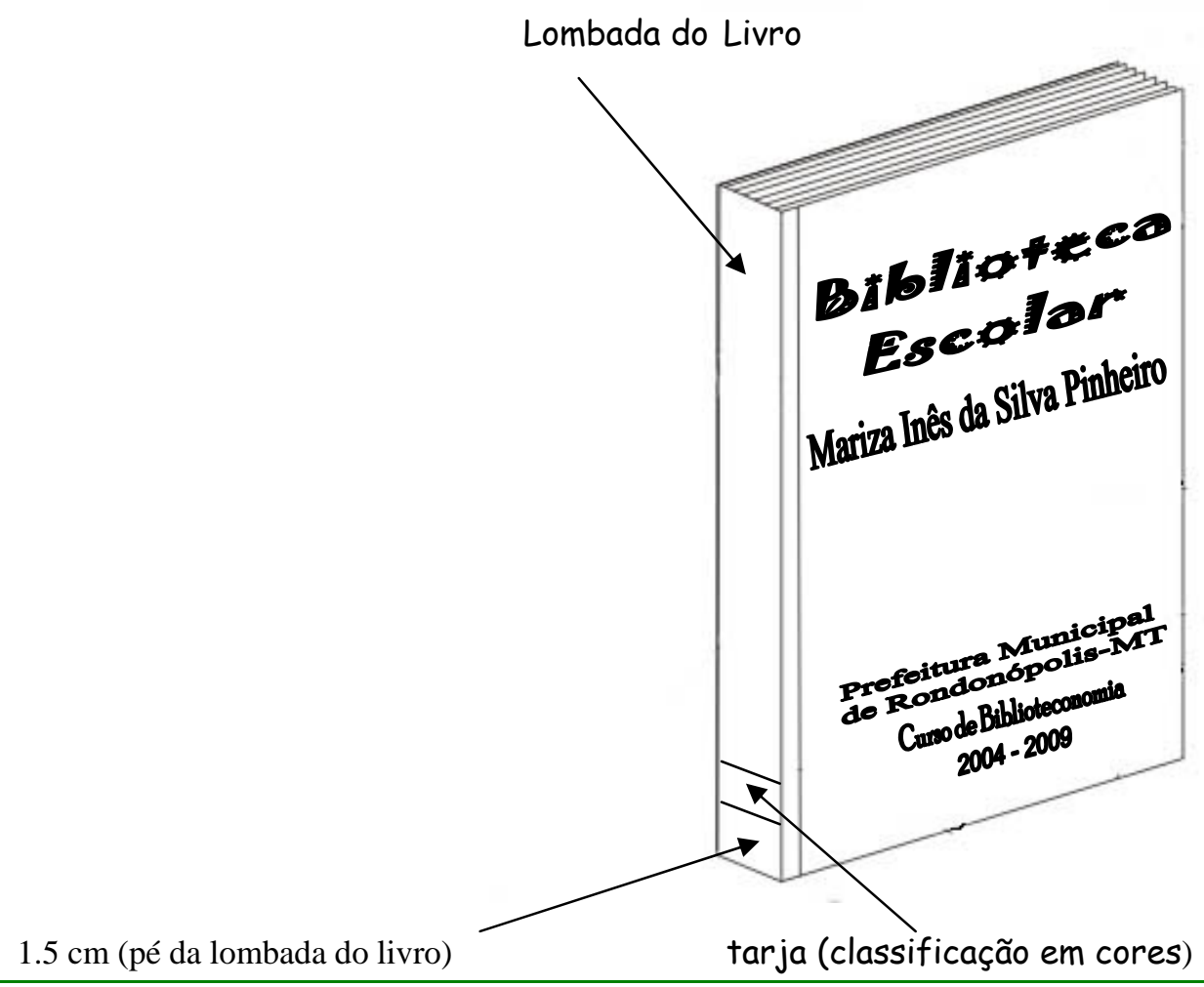

Figura 6 - Local da tarja no livro

Fonte: A autora

Neste processo de classificação, foram confeccionadas as legendas de cores e colocadas em locais visíveis, dentro da biblioteca, informando a cor correspondente a cada área do conhecimento, e no próprio ambiente se fazia a divulgação, levando-se as crianças até as estantes e explicando-se todo o processo desenvolvido e a sua finalidade.

Com este trabalho, constatou-se que "a implantação de um sistema de classificação planejado especialmente para as crianças, irá facilitar o auto-serviço e diminuir a demanda de orientação, tornando-as independentes, além de oferecer segurança e bemestar em ambiente agradável.” (PINHEIRO; SACHETTI, 2004, p. 6-7).

\section{O PAPEL DO BIBLIOTECÁRIO ESCOLAR}

A falta de uma cultura literária, entre vários fatores, faz com que, no Brasil, a maioria da população tenha o primeiro contato com o livro na escola, ou seja, na sala de aula e, em alguns casos, na biblioteca; esse contato, muitas vezes, se dá de forma errada, devido à existência de profissionais sem nenhuma habilidade e dedicação, o que pode acarretar 
experiências negativas na vida da criança, tornando-se, mais tarde, muito difícil atraí-la para a biblioteca. Conforme alerta Silva (2006, p. 1),

[...] A interação afetiva entre bibliotecário e usuário é, em minha opinião, fundamental ao desenvolvimento de uma atitude positiva para com o processoprojeto de leitura. Acredito que todos nós tivemos experiências negativas em algumas bibliotecas deste país, principalmente quando nos deparamos com um bibliotecário "seco" frio e distante em relação às nossas inquietações e buscas.

Em vista disso, cabe ao bibliotecário escolar, por meio de seu trabalho, constituir um ambiente acolhedor para que o aluno sinta-se bem. Essa tarefa não é fácil, mas se esse profissional for comunicativo, agradável, paciente, hábil, criativo e gostar do que faz, estará no caminho certo para conquistar o estudante para a biblioteca. Corrêa et al. (2002, p. 7) enfatizam que “o bibliotecário necessita de uma boa comunicação com os estudantes, deve ser agradável, gostar de servir, ser criativo e responsável, porque do seu trabalho dependerá o resultado das pesquisas dos estudantes”. Neste contexto, a orientação deve ser vista pelos alunos como uma saudação de boas-vindas e um oferecimento de apoio, pois somente assim eles se sentirão confortáveis e relaxados no novo ambiente, ao invés de intimidados e desconfiados. (CARVALHO, 1981, p.24).

Constata-se facilmente que a maioria das bibliotecas escolares enfrenta alguns problemas no que diz respeito ao seu funcionamento, acervo e pessoal, e, por isso, pode-se destacar a criatividade como um dos pontos fundamentais para o sucesso das atividades na biblioteca. Duarte et al. (1998, p.101) consideram que [...] “um profissional habilitado, competente, criativo e interessado pode trabalhar com os poucos livros que existem e criar situações de confronto e transformação, contribuindo para a qualidade do ensino público ou privado.”

Na visão de Silva (1999), o bibliotecário visto como educador deve dedicar-se mais aos programas de incentivo à leitura, junto aos alunos, buscando apoio de outros educadores da escola; deste modo, atividades mecanizadas não devem receber dedicação integral:

A preocupação técnica exclusiva é tão prejudicial quanto a sua inexistência. O bibliotecário moderno deve ser um misto de técnico e intelectual. A sua preocupação principal não deve ser datilografar fichas perfeitas, segundo um código de catalogação, mas conhecer o conteúdo dos livros que possui, ser um guia intelectual do leitor. (SILVA, 1999 p. 79). 
É verdade que uma biblioteca desorganizada pouco servirá a seus usuários, ainda mais se o acervo for grande. Mas o bibliotecário escolar não deve prender-se ao tecnicismo e deixar de lado sua principal função, que é orientar o leitor, difundir a informação e promover a leitura. Fragoso (1996, p.2) acrescenta que "precisamos dentro de nossas bibliotecas escolares, não de guardiões de acervo, mas de articuladores de ações dinamizadores; não de contadores de livros, mas de contadores de histórias”.

Segundo Corrêa et al. (2002, p. 7), a tarefa de orientar o aluno na utilização da biblioteca, e principalmente, o de despertar nele o gosto pela leitura são atribuições mais reveladoras da natureza educativa do trabalho biblioteconômico na escola.

Um dos processos mais dinamizadores dentro de uma biblioteca escolar são as atividades de incentivo à leitura. Dentre elas podem-se destacar a contação de histórias como sendo uma das mais importantes. A arte de contar histórias faz parte de uma cultura milenar que, no passado, transmitia-se de pai para filho; era comum as crianças se reunirem em volta dos pais ou avós para ouvir histórias. Nos dias atuais, este se tornou um ato incomum, e muitas crianças têm a biblioteca escolar ou infantil como a única alternativa para realizar tal desejo. Assim, a biblioteca infantil, conforme observam Pinheiro e Sachetti (2004, p.3), é de vital importância para a cultura nacional. É uma necessidade, visto que não existem mais 'amas' nem avós que se interessem pela arte de contar histórias.

Verifica-se, enfim, por meio da literatura que trata do assunto, que toda ação desenvolvida em uma biblioteca escolar deve ser de valor cultural e educativo, rumo ao crescimento educacional e intelectual da criança.

A biblioteca escola é, ainda, segundo Pinheiro e Silva (2007), um ambiente educacional e, portanto, deve haver integração efetiva da mesma ao processo pedagógico, para que brote o saber transformado em conhecimento e utilizado nas experiências cotidianas, propiciando o amadurecimento intelectual e, principalmente, o fortalecimento dos vínculos afetivos e sociais nos alunos.

Pinheiro e Oliveira (2003) salientam que o profissional que trabalha na biblioteca deve saber que é o protagonista, nesta, no papel de constituir, organizar e enriquecer o acervo, 
assim como de tornar conhecidos os recursos da biblioteca. Deve, também, ter ação administradora, o que torna necessário que ele conheça muito bem sua clientela para que possa disponibilizar recursos informacionais adequados a cada fase.

\section{CONSIDERAÇÕES FINAIS}

Diante do exposto e da observação in loco, verifica-se que o referido convênio entre o curso de Biblioteconomia e a Prefeitura de Rondonópolis vem apresentando um resultado positivo nas bibliotecas escolares. Os diretores das escolas estão satisfeitos com as atividades apresentadas, os discentes de Biblioteconomia estão adquirindo um aprendizado para sua futura profissão, e os alunos das escolas apresentam um interesse muito maior em procurar e retirar os livros indicados pelas cores, seja para leitura ou simplesmente para olhar as figurinhas.

A organização pela classificação em cores, além de facilitar a busca, tornou as bibliotecas mais vivas, mais coloridas, deixando os alunos mais curiosos pelos gêneros dos livros e, conseqüentemente, pela leitura.

Anteriormente ao trabalho realizado, as bibliotecas não tinham qualquer tipo de organização e de atividades em seu próprio espaço. A biblioteca da escola era um local sem vida, um ambiente totalmente desprovido das características que dela se espera: um local dinâmico, alegre, capaz de oferecer a aproximação da criança ao mundo literário. Hoje, com a presença dos estagiários de Biblioteconomia, é notória a diferença, começando pelo acréscimo da presença das crianças.

Por outro lado, antes do inicio deste convênio, alguns professores nem visitavam a biblioteca, e alguns o faziam raramente; eles pareciam considerar que a biblioteca não era interessante para o desenvolvimento da leitura com os alunos. Acredita-se que a situação tenha mudado, pois constatou-se que a biblioteca passou a ter outra importância na escola, ou seja, um reconhecimento considerável por parte dos alunos, professores e diretores, recebendo todo o apoio necessário para desenvolver suas atividades.

(c) Revista Digital de Biblioteconomia e Ciência da Informação,Campinas, v.7, n. 1, p. 163-179, jul./dez. 2009- ISSN: 1678-765X. 
Sabe-se que, na biblioteca escolar, o bibliotecário e o professor devem trabalhar juntos para que obtenham resultados positivos, e em muitas escolas obteve-se esta mediação. Sales (2004, p. 56), ressalta a importância do papel do profissional bibliotecário, afirmando que, "uma vez ciente de seu papel de agente escolar, ciente de suas responsabilidades pedagógicas que são diretamente relacionadas ao aluno e ao trabalho do professor, o bibliotecário escolar pode mostrar à escola sua importância dentro do contexto educacional.”

Em sentido semelhante, vê-se em Carvalho (2003, p. 23) que o bibliotecário e o professor são “mediadores da leitura” e devem ser "leitores críticos” capazes de distinguir a "boa literatura infantil e juvenil” daquela “circunstancial”, de “fórmula simplificada [...]”.

A maioria dos estagiários envolvidos neste projeto, por sua vez, demonstrou grande satisfação pelo trabalho realizado. O estágio proporcionou-lhes experiências que eles dificilmente poderiam vivenciar em sala de aula.

Trata-se, na verdade, de uma experiência ímpar, tanto para a coordenadora como para os acadêmicos, que vivenciaram, durante todo esse processo; uma contribuição valiosa para o exercício dos futuros bibliotecários.

Analisando o trabalho de quatro anos, sugere-se que a Prefeitura contrate, através de concurso público, profissionais bibliotecários, para atuarem na coordenação dessas bibliotecas. Com a presença destes, será possível oferecer para as crianças mais atividades de incentivo à leitura, tais como a hora do conto, histórias, teatros, fantoches, pinturas e desenhos e outras, já que, segundo Pinheiro e Oliveira (2003), enfatizam que este profissional é o intermediário entre o acervo e o usuário, tratando tecnicamente a informação, cuidando para que as fontes informacionais, postas à disposição dos educandos, sejam atualizadas e próprias para a fase em que estes se encontrem inseridos. Paralelamente, deve o bibliotecário esforçar-se por consolidar a biblioteca como um espaço dinâmico, pronto a servir os estudantes com eficiência e presteza. É necessário, também, que ele esteja sempre disposto a motivar os usuários, atendendo-os de forma agradável, atuante e dinâmica. A participação dos bibliotecários com os discentes de Biblioteconomia neste processo elevará a qualidade de todas as atividades da biblioteca, favorecendo o foco principal: o aluno.

(c) Revista Digital de Biblioteconomia e Ciência da Informação,Campinas, v.7, n. 1, p. 163-179, jul./dez. 2009- ISSN: 1678-765X. 
A nova realidade das bibliotecas da rede municipal de Rondonópolis é visível àqueles que conheceram as bibliotecas antes do trabalho dos estagiários.

A organização e as atividades a favor da leitura, juntamente com os professores, têm resultados satisfatórios.

Conforme relato de Santos (2008), os estagiários de Biblioteconomia não tiveram nenhuma dificuldade na organização com a classificação por cores, sendo possível perceber a independência tanto dos alunos como dos professores na busca dos livros nas estantes.

Portanto, evidencia-se que adotar medidas que facilitem o acesso à informação é extremamente necessário em uma biblioteca. Em se tratando de biblioteca escolar, cujo público, na grande maioria, é infantil, requer-se uma atenção especial na escolha do sistema de classificação, e a classificação em cores, como se pôde verificar, apresenta as características necessárias para uma satisfatória recuperação da informação pelas crianças.

\section{REFERÊNCIAS}

CARVALHO, Maria da Conceição. Educação de usuários em bibliotecas escolares: considerações gerais. Revista de Biblioteconomia, Brasília, jan./jun. 1981.

CARVALHO, Maria da Conceição.Escola, biblioteca e leitura. In: CAMPELLO, Bernadete Santos et al. A biblioteca escolar: temas para uma prática pedagógica. Belo Horizonte: Autêntica, 2003. p. 21-23.

CORRÊA, Elisa Cristina Delfini et al. Bibliotecário escolar: um educador? 2002. Disponível em: $<$ http://www.acbsc.org.br/revista/ojs/include/getdoc.php?id=778prod=pdf $>$. Acesso em: 19 jan. 2008.

DUARTE, Eneide Nóbrega et al. Bibliotecas escolares no município de João Pessoa - PB: diagnóstico. Informação \& Sociedade, João Pessoa, v.8, n.1, p.80-105, 1998.

FRAGOSO, Graça Maria. Biblioteca escolar: a bela adormecida precisa acordar. AMAE educando, São Paulo, ano 29, n. 263, out. 1996. 
Disponível em: <file://c:|Elias\Biblioteconomiala bela adormecida precisa acordar_arquivos \bibvirt.futuro.usp_... graças.ht> Acesso em: 18 nov. 2007.

PACHECO, Raquel. Incentivo ao uso da biblioteca nas séries iniciais: relato de experiência. Revista ACB, Florianópolis, v.12, n.2, p.303-310, jul./dez.2007.

PINHEIRO, Mariza Inês da Silva; OLIVEIRA, José Aparecido Venâncio de Oliveira. Biblioteca escolar e a informática educativa: uma integração que pode dar certo. 2003. Disponível em: <http://www.eci.ufmg.br/gebe/downloads/314.pdf $>$. Acesso em: 1 set.2008.

PINHEIRO, Mariza Inês da Silva; SACHETTI, Vana Fátima Preza. Classificação em cores: uma alternativa para bibliotecas infantis, SEMINÁRIO BIBLIOTECA ESCOLAR: ESPAÇO DE AÇÃO PEDAGÓGICA, 3.,2004, Belo Horizonte. Anais... Belo Horizonte: UFMG, 2004. Disponível em: <http://www.eci.ufmg.br/gebe/downloads/319.pdf>. Acesso em: 20 maio 2008.

PINHEIRO, Mariza Inês da Silva; SILVA, Edileusa Regina Pena da. Informação, educação e biblioteca escolar: proposta de interação com o bibliotecário mediador na seleção e produção de conteúdos informacionais nas redes escolares em RondonópolisMT. In: CBBD-CONGRESSO BRASILEIRO DE BIBLIOTECONOMIA, DOCUMENTAÇÃO E CIÊNCIA DA INFORMAÇÃO, 22., 2007, Brasília. Anais...

Brasília: $\quad$ FEBAB, 2007. Disponível em:
<http://www.febab.org.br/XXII_CBBD/xxii_cbbd.htmt>. Acesso em: 15 dez. 2007.

SALES, Fernanda. O ambiente escolar e a atuação bibliotecária: o olhar da educação e o olhar da biblioteconomia. Encontros Bibli: Revista Eletrônica de Biblioteconomia e Ciência da Informação. N. 18, $2^{\circ}$ sem. 2004. Disponível em: <http://www.periodicos.ufsc.br/index.php/eb/issue/view/87>. Acesso em: 20 out. 2008.

SILVA, Ezequiel Theodoro da. Teoria e prática da leitura. 30 jan. 2006. Disponível em: $\quad<$ http://www.feedraider.com/item/111110/extrabilis-acadmica/biblioteca-escolarmarlene-santos-la carmona/-15k>. Acesso em: 23 jan. 2008.

SILVA, Waldeck Carneiro da. Miséria da biblioteca escolar. São Paulo: Cortez, 2 ed., p.119, 1999.

SANTOS, Sandra Monteiro de Barros. Um olhar sobre a biblioteca escolar na cidade de Rondonópolis-MT. Rondonópolis: a autora, 2008. (Trabalho de Conclusão de Curso).

SIMÃO, Maria Antonieta Rodrigues; SCHERCHER, Eroni Kern; NEVES, Iara. Classificação em cores: uma alternativa para bibliotecas infantis, 1993. Disponível em: <http.//www.eci.ufmg.br/gebe/downloads/319.pdf.>. Acesso em: 05 fev. 2008.

VENEGAS, Antonieta Ubillo. Clasificación por colores en bibliotecas para niños: proponiendo el código Junior en colores. 2005. Disponívela em: $<$ http://eprints.rclis.org/archive/00005508/01/Clasificacion_por_Colores.pdf.>. Acesso em: 01 out. 2008. 


\section{Mariza Inês da Silva Pinheiro}

Profa. do Curso de Biblioteconomia da UFMT. Campus Rondonópolis - MT - Brasil.

mariza.ines@terra.com.br

Recebido em: 01/07/2009

Aceito para publicação em: jan/2009 